\title{
CiUdAd, Fiesta y PODER EN EL MUNdo CONTEMPORÁNEO
}

\author{
Adrià Pujol Cruells
}

Resumen: Alguna vez se dijo que la fiesta popular moriría en el medioambiente propio de las sociedades industrializadas. Se dijo que, rota la comunidad rural, las fiestas y el ritual se desmenuzarian, perdidos su sentido y fuerza de cohesión. Lejos de ser así, la fiesta todavia es un mecanismo ritual que las sociedades, sean de la tesitura que sean, utilizan periódicamente con un fin terapéutico. La fiesta cose, fabrica coágulos sociales, y lo hace allí donde parecía que la modernidad acabaría con las formas arcaicas de sociabilidad. La fiesta es un campo de batalla simbólico, cuando los grupos sociales, a veces antagónicos, exigen celebrar la calle y la plaza.

Palabras clave: fiesta, ritual, poder, sociedad.
Abstract: It was said some time that the popular festival expressions would die in the environment of the industrialised societies. It was said that, once the rural comunity broken, festivities and rituals would crumble, lost their sense and power of cohesion. Far from that scenario, the celebration is still a ritualistic mechanism that societes, whatever circumstance they have, use periodically with a therapeutical purpose. The festivity sews, builds social clotting agents, and it does so in places where it looked like modernity would finish with archaic forms of sociability. The party is a symbolic battlefield, whenever social groups, sometimes antagonistic, ask for celebration on the street and the square.

Key words: celebration, ritual, power, society.

\section{Motivos e introducción}

$\mathrm{E}$ stos papeles querrían ser el testimonio de cómo las sociedades urbanoindustriales de las últimas décadas han sido y son el escenario de una vieja querella, que tiene en la fiesta sus objetos y objetivos. La fiesta ha persistido en ser un artefacto de expresión y acción sociales, un dispositivo donde vemos desplegarse modelos de acción colectiva y la dramatización de las emociones y sentimientos que
Adrià Pujol Cruells, licenciado en antropología social y cultural por la Universidad de Barcelona, y diplomado en DEA (maestría) por la misma universidad, profesor de antropología social y cultural en ELISAVA, Escuela de Grado Superior de Diseño, vinculada a la Universidad Pompeu Fabra de Barcelona, especialidad: religiosidad moderna, inmigración, fiestas populares, correo electrónico: adriam@telefonica.net. 
alimentan la vida social. En cuantiosas metrópolis modernas las fiestas aún sirven para que aquellos que viven juntos, en unas mismas coordenadas de tiempo y espacio, nunca dejen de ser conscientes de las contradicciones que hacen posible su convivencia, a pesar de todo. La fiesta todavía es el instrumento que permite a una sociedad, urbana e hipercompleja, existir como algo más que una entelequia y existir, además, reclamando y obteniendo el derecho a usar intensivamente su espacio natural, que son los exteriores cotidianos donde la gente se encuentra: la calle y la plaza.

Consecuentes con su importancia, conscientes de la naturaleza estratégica de las energías que la fiesta reúne o desencadena, las instituciones políticas o las técnicas del marketing consumista intentan como sea parasitar este mecanismo fundamental de la musculatura social, para convertirlo en instrumento al servicio de sus intereses en materia de autolegitimación y promoción de propósitos y valores. A menudo consiguen parcialmente sus objetivos, y determinadas fiestas son objeto de apropiación institucional o comercial, y son convertidas en voceros de las consignas oficiales o proscenios a disposición de la sugestión publicitaria.

Ahora bien, si es cierto que podemos contemplar cómo las instancias gubernamentales o las marcas comerciales pueden usurpar espacios festivos, generados a ras de suelo por la propia sociedad, no es menos cierto que esta sociedad que ve alienadas sus expresiones festivales puede, a modo de venganza, apoderarse de celebraciones inventadas o auspiciadas desde arriba, convirtiéndolas en manifestaciones propias, reconvirtiendo o ignorando los significados institucionales asignados. Esta doble tendencia tantas veces registrada antes y alrededor del mundo, de apropiación institucional o comercial de las fiestas populares —en el sentido de generadas por la sociedad para expresar sus condiciones de realidad o de posibilidad - y de apoderamiento popular de fiestas promocionadas inicialmente con factura artificial, continúa produciéndose en nuestras metrópolis, a lo largo y ancho del planeta, en plena era tecnológica. Se trata de una dinámica, en cualquier caso, que arranca a principios de los ochenta, y que fue ampliamente reseñada por Boissevain (1992).

De igual manera podemos comprobar qué ocurre cuando esta fuerza de doble dirección no consigue ninguna de sus metas. Según Delgado (1992: 47), el resultado de este fracaso, de esta dimisión de mutuo aprovechamiento es, por un lado, el de las fiestas populares que los poderes políticos o económicos menosprecian, vista su inutilidad en orden a ser capitalizadas para sus intereses; por otro lado, hay fiestas promovidas desde el poder, organizadas al margen o de espaldas a la ciudad, pero que paradójicamente apelan a la masiva participación de la ciudadanía.

En medio queda la capacidad de auto-organización que las entidades vecinales, los colectivos y las asociaciones despliegan, cada vez con más dificultades, en los barrios de algunas ciudades, sea con la participación testimonial de los poderes políticos, sea en un régimen de autogestión, donde la falta de recursos favorece la creatividad, la imaginación y la implicación directa de los agentes en el proceso de gestación y desarrollo de las celebraciones.

Quisiera aportar algunas consideraciones para el estudio de las fiestas en ámbitos urbanos, quizás esos sitios en proceso de despersonalización o, por el contrario, lugares aquejados de una excesiva teatralización, fruto de los embates del turismo, las transnacionales, las migraciones, la densidad poblacional y la globalización, todos ellos elementos que saturan el pulso social de algunas de las grandes ciudades actuales. Al mismo tiempo querría exponer brevemente lo que entiendo por urbano. A mi parecer, y resumido de manera intolerable, cuando hablamos de lo urbano no se trata tanto de una estructura más o menos grande de calles y plazas, una aglomeración humana o un cierto tipo de edificios. Por el contrario 
creo que lo urbano es más bien una cualidad de la socialización, contemporánea y en franco avance. Tanto es así que para este breve análisis da igual que la fiesta acontezca en un pueblito. Los turistas, la televisión, los antropólogos y la Coca-cola que se consuma, convertirán, entre todos, el espacio social en algo transnacional, y la socialización devendrá urbana.

Tengo que decir, también, que las siguientes consideraciones son el fruto de mis investigaciones, por más de cinco años, en el contexto de la ciudad de Barcelona, por lo que muchos de los ejemplos que pondré, para sustentar la teoría, provendrán de esa urbe mediterránea. En paralelo mis investigaciones se han extendido a Catalunya, y por ende al Estado Español. Aun así trataré de ilustrar el discurso teórico con otros prototipos alejados de mi trabajo de campo, casos que he conocido por otros trabajos, tanto clásicos como actuales, de colegas y de autores admirados y autoras admiradas. ${ }^{1}$ Propongo, en definitiva, pautas primarias para abordar el lugar del ritual en los contextos donde, en apariencia, se dijo que estaba languideciendo.

\section{La fiesta: una vieja conocida}

Sea cual fuere la perspectiva que adoptemos para hablar de la fiesta como dominio teórico y analítico, nos será fácil consensuar que nos acercamos a una de las expresiones más vehementes que puede adoptar una determinada sociabilidad autoconsciente. Dicho de otra forma, la fiesta crea o quiere crear sociedad, y se quiere que esto ocurra entre personas que constituyan una comunidad integrada orgánicamente, un grupo de gente que conviva día a día. Pero estas personas también podrían ser unas perfectas desconocidas hasta entonces, gente que, gracias al nexo festivo súbitamente establecido, pase a sentirse unida por vínculos tan efímeros como poderosos.
Asimismo, la fiesta establece, sanciona o renueva un compromiso entre individuos o grupos; rubrica ritualmente un pacto explícito o apenas sobreentendido; opera una sutura social invitando a los reunidos a mezclarse con una suerte de sustancia extraordinaria, que es la que se destila del microclima generado por el hecho festivo. Una unidad humana — aparte de su naturaleza- que no tenga el cuidado de recibir la confirmación que le depara el ámbito festivo, automáticamente se vuelve frágil, está condenada a desaparecer o bien a reconocer de algún modo que nunca estuvo realmente viva. Con otras palabras, la fiesta permite a los sujetos tomar conciencia y sentir que son parte integrante de una totalidad; una suma que, por momentánea que sea, los actantes notan que los supera, que la necesitan y que los necesita, pues ya se convirtieron en una parte no segregable. La fiesta, literalmente, propone a la sociedad que se recree, palabra, ésta, que no por casualidad devino sinónima de divertirse.

Es por esta causa que las celebraciones populares en realidad son jurisdicciones que dan la oportunidad a una comunidad humana - desde la pareja de enamorados a una nación, desde una etnia a un club de fans de Madonna- de ponerse ella misma en escena, de ser al mismo tiempo protagonista y espectadora de su propia epifanía. Mecanismos de comunicación, aceleradores al máximo nivel de las interacciones sociales, artefactos de mediación simbólica..., en todo el mundo, durante todas las épocas, las fiestas tienen la misión de hacer posible, de encarnar en un momento dado aquella comunidad donde cada uno se integra aunque sea de manera polémica, y que le permite a la persona saber que no se acaba en sí misma; una comunidad que no es una realidad palpable, antes se trata de un medioambiente invisible y que sólo se manifiesta en la medida que el accidente festivo le presta un vehículo para darse a conocer. La fiesta permite reificar lo que no puede ser más que una ilusión: la existencia de una comunidad integrada y orgánica basada en algún tipo de verdad, una gemeinschaft 
que la fiesta, a modo de un espejismo, permite ver y vivir como una entidad ya no tan sólo natural, sino de alguna manera sobrenatural, fundada en una tradición o en una historia mostrada como fuente de sacralidad. De esta manera no se suele discutir que la fiesta sea uno de los instrumentos más insustituibles, uno de los mecanismos que cualquier identidad compartida utiliza para cotejar periódicamente su imaginaria existencia real; sobre todo en el momento actual, constatada la pervivencia de este mecanismo por encima de los cambios vertiginosos, los vaivenes a los cuales el mundo contemporáneo somete a pueblos y individuos.

Sin embargo, esta actividad que consiste en añadir a la realidad una prótesis, una continuación simbólica, no siempre se lleva a cabo en clave armónica. Bien al contrario, en no pocas ocasiones las fiestas sirven para que afloren las contradicciones y los antagonismos, el fondo de lucha y de conflicto que en condiciones cotidianas apenas llega a vislumbrarse. He aquí por qué la arena festiva resulta tan adecuada a fin de contemplar cuáles son las relaciones de poder en una sociedad, cómo interactúan principios ideológicos, concepciones del pasado con proyectos de futuro que son, por definición, incompatibles, y que conviven posponiendo su permanente tendencia al enfrentamiento. De ahí la dimensión crispada y tan pronto sacudida que tienen ciertas fiestas, si no es que todas las fiestas contemplan la convulsión en algún grado u otro: la voluntad que transpiran de recordarnos que ninguna forma de unión supera las virtudes del conflicto como máquina de cohesión social.

En resumen, todas estas características han hecho de la fiesta un terreno propicio para el descubrimiento de las dialécticas políticas y las correlaciones sociales de poder, es decir, un lugar y un tiempo para que se expliciten opciones de y en contra de un determinado estado de las cosas; un campo de batalla en el cual se rozan o chocan los valores dominantes y sus respectivas impugnaciones. Por eso Lévi-Strauss (2001) consigna un caso curioso acontecido en una ciudad mediana de Francia, en el año 1942. Las autoridades eclesiásticas locales quemaron un muñeco de paja, un Papá Noel — o Santa Claus - en la plaza, delante de una multitud de niños boquiabiertos. Se decía que el barbudo estaba pervirtiendo la Navidad, con su traje rojo - invento de la Coca-cola, pues siempre fue verde- desplazando los valores cristianos de la fiesta del nacimiento de Cristo. Pero lo cierto, nos dice Lévi-Strauss, es que se estaba escenificando un rechazo a la saturación del mercado francés con productos norteamericanos, en un tiempo en que la guerra mantenía en un bajo nivel la producción europea. Debido a la presión de las autoridades civiles, al día siguiente Papá Noel fue resucitado, en la misma plaza, delante de los mismos niños.

Más: esta cualidad de la fiesta, en tanto que territorio de encuentro o choque social, ¿continúa vigente? $\mathrm{Al}$ respecto se constatan algunos argumentos que tienden a repetirse cuando se inaugura cualquier discusión sobre dicha, al mismo tiempo, institución, dispositivo y técnica cultural que llamamos la fiesta. Aparte de las discusiones a propósito de cuál es la definición que más se le ajusta, de todas las propiciadas por las ciencias sociales, la historia cultural o la filosofía, cada vez resulta más inevitable que aparezca la cuestión de si todavía la fiesta sigue viva, si está muerta o moribunda, pues se argumenta que su sentido auténtico se ha extraviado o fue usurpado por algún tipo de instancia maligna y distorsionante, ya sea el poder, el consumismo, el turismo o el espectáculo trivializado propio de la cultura de masas. Y si además el contexto al cual nos remitimos es el específicamente urbano y contemporáneo, estas cuestiones se agudizan, y no es insólito que se acabe terminando en una suerte de triste canto plañidero a lo que fueron y ya no son las fiestas populares en las metrópolis o villas actuales.

En relación con todo esto, tendría que resultar de lo más pertinente aquella especie de manía que corresponde plenamente a la antropología como oficio 
analítico, y que no consiste en otra cosa que en el descubrimiento de todo aquello viejo o repetido que se esconde detrás de lo que se muestra, o nos es intencionalmente mostrado, como nuevo y hasta provocador. No se trata, es obvio, de negar los cambios, pero sí de dejar su constatación en manos de sociólogos y sociólogas, historiadores e historiadoras, mientras nos centramos en el ejercicio de este tipo de dejá-vu antropológico que, por la importancia central que otorga al método comparativo, se obstina en reconocer inercias y repeticiones en los dispositivos de acción social que a menudo se nos presentan bajo disfraces inéditos. Esto no quiere decir que no se reconozca que la fiesta — como recurso al servicio de determinadas ideologías culturales y ciertos sistemas de acción social - no haya cambiado. Ab initio corresponde descubrir que, en efecto, hay fiestas, y que éstas, en tanto que sistemas rituales secuenciados, continúan cumpliendo su tarea de convertirse en recursos culturales al servicio de alguna comunicación simbólica. Me refiero a sistemas formalizados - convencionales-, estereotipados — rígidos en todos o en sus elementos axiales-, condensados — con acumulación y síntesis de significados_ $-\mathrm{y}$ redundantes - recurrentes en relación con ciertas circunstancias.

También podemos llegar a la conclusión de que las fiestas todavía son lo que siempre fueron: actos preformativos, en todas las acepciones que el vocablo tendría, es decir, expresiones que cobran sentido en un determinado contexto, acontecimientos vividos intensamente y promotores de adhesión alrededor de determinados valores considerados axiomáticos ( $c f r$. Tambiah, 1985). Y todo esto es la fiesta, y lo es haciendo lo que siempre hizo, que no es sino adaptarse a las mismas metamorfosis sociales a las cuales se adaptaba y de las cuales se servía y se sirve como mecanismo de representación y modelo referencial de actuación.

En las metrópolis los agentes han cambiado, es cierto; los temas en muchos casos también, al igual que pasa con las formas. Ahora bien, lo que ha cambiado poco o nada es la misma cualidad de la fiesta como resorte para la dramatización de unos estados de ánimo, el escenario de los cuales nunca dejaron de ser la calle y la plaza, la intemperie debajo la cual un grupo humano podía existir más allá de una abstracción, el entarimado sobre el cual inscribir discursos a menudo paradójicos, madejas hechas a partes iguales de consenso y conflicto, en las que las instrumentalizaciones dibujaban una filigrana de intereses y gestualidades entrecruzadas (Delgado, 1992).

Asimismo, una vez constatada esta virtud de la fiesta como mecanismo para actuar y para pensar, lo que cabe preguntarse es: ¿para pensar y para hacer qué? En paralelo, si estamos de acuerdo con que la fiesta también es un dispositivo de comunicación, no es menos urgente responder a la cuestión de qué es aquello que comunica, de qué habla o de qué obliga a hablar a aquellos que son al mismo tiempo los que hablan y los que escuchan, los emisores y receptores del mensaje. Es decir, una vez hemos establecido que la fiesta es una mera energía disponible y que, cuando toca, es dispuesta, el tema que podría intrigarnos es al servicio de qué, instrumento en manos de quién, litigada por cuáles sectores que la querrían vehículo propio para proclamar y actuar. Ya asumimos como premisa teórica, siguiendo a Ariño (1992:15), que las fiestas son al mismo tiempo transitivas y reflexivas, en la medida de que una determinada colectividad celebra alguna cosa y se celebra a sí misma; pero..., ¿en qué términos?

En todo caso, mis análisis de la fiesta en Barcelona - lo que debería ser lo mismo que el análisis de sus usos como dispositivo de enunciación e intervención sociales - podrían demostrar la bondad de este principio que se acaba de enunciar, a propósito de la necesidad antropológica de poner de manifiesto reiteraciones de mecanismos ya conocidos en lo que respecta a la forma, estructura y función, sin dejar de advertir sobre su capacidad para amoldarse a 
condiciones que siempre son inéditas. En primer lugar, con todas las mutaciones que se quieran reconocer, recibiendo como reciben la marca de los tiempos, las fiestas siguen siendo lo que eran. Me refiero a técnicas de subrayado de un determinado tiempo y de unos determinados espacios que quedan, al margen de cuáles sean sus contenidos concretos, colocados en una especie de estado de excepción. De entrada porque se han visto transformados estéticamente; después, una vez preparados como proscenio, en la medida que fueron convertidos en escenario para una determinada efervescencia colectiva, el contenido de la cual suele ser, como ha escrito Handelman (1990:47), un género de metacomentario sobre las condiciones de la vida ordinaria. En fin, como dijo Velasco:

...la fiesta es un contexto complejo en el cual tiene lugar una intensa interacción social, y un conjunto de actividades y de rituales, junto con una profusa transmisión de mensajes, algunos de ellos trascendentes, otros no tanto, y un desempeño de roles peculiares que no se ejerce en ningún otro momento de la vida comunitaria; y todo esto parece susceptible de una carga afectiva, de una tonalidad emocional, de forma que las gentes [sic]y su acción social parecen encontrarse, y crear un ambiente inconfundible, un ambiente de fiesta (Velasco, 1982:8).

Por lo tanto, podríamos asumir la pertinencia de esta definición de la fiesta como tecnología que, según queramos mantenernos fieles a las matrices teóricas prestadas por Weber o Durkheim, tanto da, consiste en dotar de carisma o de sacralidad un tiempo y un espacio que de golpe se han convertido en especiales, en el sentido que se ven revestidos de un clima distinto y singular, un tipo de atmósfera extraordinaria, forma formalizadora y al mismo tiempo deformadora, a la cual le podría corresponder no importa qué contenido. Es en esto en lo que hay que insistir: en esta virtud que la fiesta sigue ejercitando, ahora y en todos lados, de desfigurar el tiempo y el espacio sociales: abriendo un intersticio y llenándolo después de ambigüedad estructural, fundando una especie de paréntesis en el flujo de la vida cotidiana, distorsionando, difuminando, realzando o dislocando las trastiendas habituales de los días ordinarios, para hacer de ellos otra cosa.

\section{Sangre y fiesta}

Más allá de estas consideraciones de tipo general, lo que nos interesa no es tanto cómo las fiestas siguen siendo fiestas en las grandes ciudades, es decir, la apropiación de espacios y tiempos en manos de coágulos humanos que se citan en un punto y momento, para hacer cosas sobre todo simbólicas, en el sentido de no instrumentales. También nos interesa la manera como esta técnica de manipulación de los entornos cotidianos puede ser a su turno manipulada, para hacer de ella el soporte de una cierta expresividad conectada a determinados intereses políticos oficiales, al mismo tiempo que se niegan, se olvidan o hasta se persiguen modalidades de acción festiva menos o nada monitorizables desde la Administración. Las recientes manifestaciones mundiales contra la guerra en Irak — verdaderas rúas, coloridas y ruidosas — vendrían a fundamentarla.

De todas estas cuestiones habría, no obstante, precedentes teóricos y empíricos a tener en cuenta. Una vez más, el caso español me parece ilustrativo. En primer lugar, y a un nivel inmediato, tendríamos los estudios que abordaron el tema del proceso que acompañó la llamada Transición Democrática, y que a partir de 1975 consistió en una revitalización de las llamadas fiestas populares, celebraciones olvidadas, perseguidas o mal vistas durante la dictadura franquista, es decir, por más de 35 años. Muerto el dictador, a estas fiestas tradicionales malditas se les añadieron algunas recién inventadas o reinventadas, aunque todas ellas resultaron el soporte manifiesto de una voluntad 
compartida por muchos de recuperar unos espacios - la calle, la plaza - que habían estado rigurosamente vigilados durante la dictadura para evitar en ellos cualquier muestra de desafecto hacia el régimen político fascista y dominante. El cómo estas manifestaciones festivas fueron siendo asumidas con relativa rapidez por las nuevas autoridades es una cuestión que también fue investigada, especialmente en casos como el de Madrid (Cruces, 1992). El cuadro descrito por este tipo de estudios tiende a repetirse: advenimiento de un nuevo régimen político, predispuesto a encontrar en el uso intensivo del espacio público una fuente de recursos legitimadores y un marcador simbólico eficaz al servicio de los nuevos valores que iban a orientar la administración política de la sociedad; y, más concretamente, la llegada al poder de partidos nominalmente de izquierdas en condiciones de reclamar la vieja eficiencia retórica de las fiestas civiles de inspiración republicana, para ponerla a disposición de una determinada ideología cultural, muy vinculada a la promoción de los ideales de participación y ejercicio de la ciudadanía.

Tampoco hay carestía de aportaciones en torno al papel que desempeña cierto tipo de fiestas que se adaptaría bastante bien al modelo que la antropología ha estudiado bajo el epígrafe de ritos de rebelión, es decir, ceremonias en las cuales las relaciones de dominación quedan subvertidas momentáneamente y se produce una inversión entre papeles de sometedores y sometidos. Las fiestas del caos aceptadas -incluso previstas en el marco del sistema ritual institucionalizado- en muchas sociedades son un fenómeno extendido y en todos lados ejecutan la misma función garante de la continuidad de un determinado estado de cosas; por momentos se marchita un medioambiente marcado por la estratificación y la jerarquización, a partir de ponerlo en cuestión o de incluso triturarlo en algunos episodios festivales. Hablaríamos entonces de dramas rituales autorre- ferenciales, en los cuales se escenificaría una situación de crisis. El tema fue abundantemente estudiado (véase Balandier, 1990), y siempre para remarcar la existencia activa de mecanismos homeostáticos o de retroalimentación negativa, cuya función es precisamente la de mantener estable un determinado sistema societario, operando a modo de termostatos que regulan la presión social, es decir, permitiendo escenificar periódicamente las contradicciones y las luchas que dormitan larvadas en las condiciones ordinarias. Las Saturnales romanas obedecían a este esquema.

Pero al mismo tiempo que un determinado orden social se autorregula a base de cuestionarse de la manera más rotunda, y de estallar durante un breve período, toda forma de poder puede tomar conciencia de hasta qué punto su dominio es relativo, precario, incapaz de controlar del todo unas energías sociales que este tipo de fiestas despliega, y que en cualquier momento podrían llevar hasta las últimas consecuencias su virtualidad con tal de modificar las condiciones de la realidad. Recordemos que en Europa y en Brasil hay documentados carnavales que acabaron en revueltas, celebraciones del Corpus Christi derivadas en motines y saqueos, etcétera (Burke, 1997).

De cualquier modo, es aquí cuando surge una cuestión ya clásica en la antropología de la fiesta: la de la lábil frontera que separa ciertas celebraciones de lo que serían explosiones de violencia, hasta de la guerra como su expresión más extrema. Esta visión fue cultivada sobre todo a partir de las intuiciones de autores como Roger Caillois o Georges Bataille, quienes enfatizaron en su momento la manera como la fiesta, con su contenido consustancial de desbarajuste y frenesí, constituiría una evocación-invocación del nacimiento y del fondo violento de toda sociedad, una activación periódica y protocolizada de energías sobrentendidas, la tarea de las cuales sería advertir el disentimiento crónico del cual estaba hecha la convivencia. Un punto de vista similar resultaría de aplicar — como algunos 
autores y autoras han hecho_ — a la fiesta los principios de double bind o doble vínculo de Bateson (cfr. Gil Calvo, 1991), viendo las fiestas como marco de intensificación de las instrucciones paradójicas —órdenes que ordenan desobedecer_- ámbitos privilegiados en los cuales se comprueba el funcionamiento esquizofrénico de toda sociedad, a través de mecanismos de mantenimiento del orden que no siempre tienen garantizada su eficacia reguladora.

Lógica, pues, del paso constante del caos creador al cosmos creado, que haría comprensible por qué tan a menudo las fiestas pueden conocer súbitos y no previstos momentos de aceleración de la sustancia violenta de la cual estaban hechas, como en el caso de las muertes anuales que se dan en las carreras de caballos, en el pueblo guatemalteco de Todos los Santos, precisamente el día de Los Muertos; fiestas que pueden pasar de las agresiones simbólicas entre segmentos sociales enfrentados ritualmente o contra potencias representadas como anticomunitarias — tal es el caso de la quema de Judas en muchos países barnizados de catolicismo - a formas de violencia real, lesivas contra cuerpos, propiedades o identidades, al estilo de las peleas entre celebrantes o las agresiones - reales o simbólicas - que pueden sufrir los visitantes extranjeros en los carnavales de San Juan Chamula (Altos de Chiapas). La historia está rellena de ejemplos de este fácil tránsito de la fiesta a la revuelta, es decir, de que se haga positivo un mecanismo de feedback que en un principio tenía que ser negativo. La historia festiva de las últimas décadas en Catalunya, por ejemplo, es una prueba de hasta qué punto fue inevitable que festejos populares acabasen en desórdenes graves, en algunos casos con resultados luctuosos, en una dinámica que parece haberse agudizado en los últimos tiempos. Sólo cabe recordar los destrozos masivos que se dieron en la celebración de la Champions League en el 2006. Pero, para un sumario concreto, convendría evocar al respecto la investigación recientemente publicada a propósito de las relaciones entre las conductas festivas colectivas y apropiaciones insolentes del espacio público en Barcelona durante la segunda mitad del siglo xx (Delgado, Antebi, Horta et al., 2003).

Más específicamente, y para aludir a la muchas veces referida como la fiesta de las fiestas, el Carnaval — que sería en buena medida una concreción de esta válvula de escape social, no siempre bien gestionada, a punto siempre de desbordarse — ha sido uno de los temas más recurrentes en la antropología e historia social y cultural. En tanto que mecanismo pseudo revolucionario - pero permanentemente al punto de descontrolarse y transitar de la violencia simulada a la real, como demostró el trabajo excepcional de Le Roy Ladurie (1979) sobre los sucesos de la ciudad francesa de Romans a finales del siglo XVI-, el Carnaval ha sido uno de los grandes asuntos abordados por la historia de las mentalidades, que encontró en él una de las muestras más representativas de cómo se encarna un determinado sistema de representación centrado en la idea de las relaciones entre violencia y comunidad (para un resumen de esta amplia gama de trabajos, ver Vovelle, 1996). No se trata de repasar ahora la abundante bibliografía sobre las diferentes expresiones del Carnaval o de fiestas análogas como, por ejemplo, la Fiesta de los Locos, medieval europea. Dejando de lado esas aportaciones que pretendieron una teoría general sobre el tema -Bajtin, Ginzburg, Gaignebet, Caro Baroja, Eco, etcétera-, lo que nos interesa aquí es reconocer el valor de trabajos sobre cómo esta celebración se ha convertido en un marco para dramatizar las tensiones reales pero, eso sí, en la escenificación de un falso caos, desorden programado en gran medida, para que emerjan los contenciosos entre segmentos sociales incompatibles o antagónicos. Podrían servir de muestra los enfoques ya clásicos de los trabajos de Gillmore (1995) sobre la tarea que en este ámbito ejecutan las celebraciones carnavalescas en algunos pueblos de Andalucía (España). 


\section{Del ocio al negocio}

Por ahora también es cierto que este dispositivo de travestismo generalizado de las formas sociales, el Carnaval, se ha esparcido y ha trascendido los ámbitos específicos en los cuales la costumbre o la tradición lo encerraban, dentro de ciertas fechas en el calendario. De las prácticas de consumo de masas hasta los grandes actos civiles de protesta, todo es carnaval. Tenemos el caso del carnaval fuera del carnaval que ha conocido Barcelona con las exhibiciones de Carlinhos Brown, en los meses de mayo de 2004 y 2005; pero no se trata de un ejemplo original, pensando en la manera como Dinamarca trasladó sus carnavales a la Pentecosta, mutando también los contenidos más tradicionales en otros de tinte brasileño ( $c f r$. Henningsen, 2004). Bien lejos de las posiciones pesimistas que auguraban una desaparición inminente de los rituales de disolución y reversión de los papeles sociales, a mucha distancia de la condena a muerte que parecía amenazar aquellas fiestas en las cuales las fichas del juego social cotidiano eran removidas como para iniciar una nueva partida, parece ser que hoy por hoy todo está subsumido en una colosal dinámica de carnavalización de las relaciones sociales públicas. Sirva de ejemplo el reciente plantón que los seguidores de Manuel López Obrador ejecutaron en el Zócalo de Ciudad de México, con bailes y cantos, caricaturas y otras impugnaciones a los más altos poderes del Estado Federal. Pero no hace falta que todo sea tan espectacular. Como escribía Vovelle, "el auténtico Carnaval de hoy es la salida a bailar del sábado por la noche" (1985: 198).

Otro fenómeno, del cual la historia festiva reciente de Barcelona sería una reedición, es precisamente el del intento de institucionalización de determinadas celebraciones populares, entendiendo por populares aquellas celebraciones que de verdad son realizadas en público y por el público. Las autoridades políticas o religiosas y, en una última etapa, la mercadotecnia comercial han procurado siempre sobreponer sus referentes simbólicos en contextos festivos que ya habían demostrado su eficacia como soportes de una determinada afectividad colectiva. De esta dinámica tenemos ejemplos bien ilustrativos, dados por antropólogos y antropólogas e historiadores e historiadoras. Para casos que me son cercanos, me remito al trabajo de Belascoain (1985) sobre la institucionalización del Carnaval de Vilanova, un pueblo cercano a Barcelona. Este caso ha sido paradigmático de lo que ha pasado con muchos otros en España. En fin, una celebración recuperada después del franquismo fue perdiendo su inicial espontaneidad y su contenido subversivo, y experimentó un proceso acelerado de normativización. Una festividad, finalmente, que ha quedado en manos de los correspondientes técnicos o especialistas en fiestas, que la han sometido a reglamentaciones y rutinas uniformizadoras, y que la han colocado bajo la hegemonía de comités oficiales de la propia municipalidad.

Con todo tendríamos casos fuera de España, que nos pueden ilustrar. El Basant es una fiesta de raíces hindúes que se celebra en Pakistán, sobre todo en la megaciudad de Lahore. Parecido a la Navidad, por su importancia familiar y económica, durante el Basant la gente hace volar cometas, y se instaura una competición para derribar las de los contrincantes. El cielo y los tejados de la urbe se ven repletos de motas de colores, de hilos que cuelgan por todo el cableado eléctrico. Pero las autoridades quieren un Pakistán musulmán, por lo que en la edición del 2006 persiguieron y encarcelaron a multitud de celebrantes. El germen hindú debía ser eliminado, con la excusa, entre otras, de que los hilos son un peligro para transeúntes y motoristas, y la imagen que nos queda es la de una celda con un hombre sentado dentro, un hombre que en su regazo sostiene una cometa rota por la policía. Pero hablá- 
bamos de usurpación, más que de prohibición. Parafraseando a Hobsbawn y Ranger (1988), la invención de los carnavales brasileños acude como ejemplo. A principios del siglo xx los arrabales de Río y de Bahía conocían carnavales tumultuosos, violentísimos, que las autoridades locales fueron domesticando hasta llegar al panegírico del Brasil actual, donde los cuerpos desnudos del negro y la negra se contonean, delante de millares de espectadores y telespectadores. Lo que antes era mal visto por la curia religiosa, incluso censurado, se convirtió, en manos de las elites intelectuales y políticas, en motivo de orgullo nacional.

Visto esto, que la fiesta es a menudo un mecanismo de enunciación usurpado o inventado desde arriba, para legitimarse el poder, tampoco es una constatación inédita. Los poderes políticos, religiosos o económicos pueden, como acabamos de ver, intentar parasitar festejos ya existentes, pueden esponsorizarlos y recubrirlos de su propio discurso, pero también pueden inventarse otros, el destino de los cuales no es más que el enaltecimiento de su autoridad o servir de altavoces a sus propios objetivos disuasivos o persuasivos. En el campo de las tradiciones explícitamente religiosas, las celebraciones europeas del Corpus serían ejemplos inmejorables de la exhibición pública de la autoridad de la Iglesia Católica sobre el tiempo y el espacio sociales, a igual que en las monstruosas concentraciones de peregrinos en la Meca, utilizadas por algunos capitostes como fuerza de control emocional, social y económico. De manera análoga, las grandes puestas en escena del poder real durante el Renacimiento o el Barroco fueron atendidas justamente como esto: teofanías del poder político, en el desarrollo de las cuales el pueblo podía manifestar sus sentimientos de admiración y gratitud hacia sus gobernantes, al mismo tiempo que estos convertían su autoridad en un espectáculo grandilocuente, basado en desfiles, fuegos artificiales, comilonas colectivas... (Cardini, 1984). Y lo mismo valdría para la manera como las nuevas ideologías europeas del poder se valían para inculcar y hacer pedagogía de los nuevos valores, como se mostró en relación con el soporte festivo que requirió la didáctica de los principios republicanos en la Francia de finales del siglo xvIII (Vovelle, 1976), un proceso paralelo a la posterior erección de monumentos conmemorativos — ¿muñecos solemnes? - en Barcelona (Michonneau, 2002).

Estaríamos hablando, pues, de la base festiva de aquello que algunos autores bautizaron como teatrocracia, autoridad moral que el orden político pretende ejercer basándose en el pavoneo exagerado, los grandes encuadramientos de masas disciplinadas y los magnos decorados de cartón-piedra ( $c f r$. Balandier, 1994). No hace falta decir que podríamos encontrar multitud de manifestaciones vigentes de esta tendencia de los poderes al exhibicionismo a lo largo de todo el siglo xx y hasta la actualidad. Nos lo vienen a demostrar toda suerte de inauguraciones, celebraciones cívicas, bodas reales, festivales culturales o deportivos y otras expresiones de lo que algunos autores han definido, precisamente, como antifiestas o disoluciones festivas, entendidas como fiestas colocadas bajo imperativos de justificación y legitimación de las estructuras de la política (Escalera, 1998). Urge presentar aquí el ejemplo del Forum Internacional de las Culturas Barcelona 2004, que tendrá su segunda edición en Monterrey (México). Un tiempo y un lugar para que las autoridades catalanas y españolas, con el pretexto del diálogo cultural, pusieran en marcha una vasta operación arquitectónica, económica y de promoción en la ciudad de Barcelona. Un escenario, en definitiva, para que el poder se mostrara bajo el auspicio de lo políticamente correcto: la paz, la multiculturalidad y la sustentabilidad del medio ambiente. Un marco, al final, donde pálidos reflejos de culturas en conserva no ofrecieron nada más que folklore, eso sí, revestido de autoridad moral. La congregación de gobernantes, expertos, líderes indígenas y espectadores fue metáfora de un diálogo que no existe cuando, claro está, la fiesta termina. 
No obstante, no se puede olvidar que en estos casos puede pasar lo mismo que con la institucionalización de fiestas que habían servido para expresar descontentamientos populares y dramatizar inversiones simbólicas del statu quo. Si podemos conocer domesticaciones oficiales o comerciales de ciertos carnavales, usos comerciales del folklore - como en el caso de las calabazas de Halloween-, también se puede producir un fenómeno inverso: que las celebraciones extremadamente formales y solemnes, generadas desde arriba por los poderes eclesiales o políticos, acaben resultando algo bien distinto de lo inicialmente proyectado, y terminen como instrumentos de impugnación popular de aquellas mismas jerarquías al enaltecimiento de las cuales iban inicialmente destinadas. En España, la manera como las celebraciones de entronización patronal de la Madre de Dios de Montserrat, en 1947, patrocinadas por el nacionalcatolicismo franquista, se convirtieron en un acto de protesta antifranquista, es un ejemplo (cfr. Frigolé, 1980). Así como la quizás primera manifestación festiva y acuática de la historia, que multitud de colectivos anticapitalistas organizaron contra el Forum Barcelona 2004, invadiendo desde el mar y provocando el caos en el recinto de los fastos con banderas piratas y embarcaciones de manufactura casera.

Finalmente, nos encontramos con otra cuestión relativa a cómo estos poderes, que siempre intentan hacerse con el control de las apropiaciones populares de la calle que la fiesta desencadena - como acabamos de ver, sin tener nunca garantizado el éxito, ni tan sólo en el caso de sus propias producciones festivas-, administran la ya mencionada tendencia que éstas no dejan nunca de experimentar al ejercer formas de intensidad variable de violencia simbólica. En efecto, hay un aspecto inevitablemente frenético en la mayoría de fiestas, aún más en aquellas que representan pseudo viruelas populares o se convierten en instrumentos de censura social. Qué hacer con este contenido agresivo es un viejo problema que los poderes políticos siempre han intentado resolver como mejor pudieron. Si no han conseguido desactivar este potencial cuestionador, que toda fiesta contempla, si ni siquiera han sido capaces de temperar en la medida de lo posible la impetuosidad que comporta el tumulto festivo, la única alternativa que les queda, antes de llegar a la simple prohibición, es forzar estas fiestas aún espontáneas y autogestionadas a sobrevivir en condiciones de marginación, arrojadas a la periferia de las formas mal toleradas de expresión colectiva. En el caso de las ciudades catalanas, y de su capital en particular, la desconfianza oficial hacia las noches de San Juan o de Fin de Año — celebraciones realizadas por excelencia- sería una muestra. La persecución contra las hogueras solsticiales y las intervenciones policiales contra la gente que en ellas participaba, en las últimas ediciones, fueron la réplica municipal a su propia impotencia en el momento de someterlas a programas y regularizaciones.

\section{¿Dónde empieza o acaba la función?}

El intento de apropiación institucional o comercial de ciertas fiestas y la creación oficial de otras no son sino las pruebas de cómo es de vigente la eficacia de las fiestas - como ritos o sistemas de ritos que son- en tanto que herramientas pedagógicas, es decir, como inductores de unas determinadas orientaciones conductivas, no muy diferentes de las que la etología atribuye a los instintos entre las otras especies animales. En realidad, los rituales, las fiestas en nuestro caso, no se limitan a desplegar la maqueta de un cierto orden social establecido, exhibida delante de unos individuos pasivos que participan ecuménicamente de esta imagen proyectada e ideal del mundo. También son auténticas instrucciones de uso para esa vida social de la cual son una representación dramática. No se limitan a explicar cómo es o cómo debería ser la convivencia, sino que constituyen todo un aparato didáctico destinado a entrenar sujetos en el tipo de 
actitudes y sentimientos que se espera de ellos en cada momento. ¿Qué es el grito presidencial, el 15 de septiembre en México, o la multitud de fiestas de la independencia en muchas ex colonias?

A la manera de una alarma, o de un gatillo, los participantes en una fiesta reciben estímulos no muy diferentes de los que pueden o podrían recibir en su vida cotidiana, y son domesticados sobre el tipo de reacciones que, se entiende — desde la ideología cultural que la fiesta vehicule - deberían de experimentar. En tanto que conglomerados congruentes de símbolos, las celebraciones vendrían a ser, pues, una especie de catálogo de espuelas respecto de las cuales se esperan determinadas respuestas automáticas por parte de los individuos. Nadie espera, creo, que el día 15 de septiembre una mexicana salga a la calle y grite " $" V i v a$ Noruega!”, pero sí se contemplaría que gritara “¡Abajo México!", porque ese sentimiento sí está previsto, por dialéctica primaria, en este tipo de celebraciones. Las fiestas no se limitan, siguiendo a Geertz (1987: 91) y —más cerca de mí, aplicando este principio al sistema festivo vigente en el País Vasco—a Josefa Zulaika (1992), a ser modelos de la realidad social, sino que son, sobre todo, modelos para esa realidad social, de la cual son a la vez el mapa y la brújula.

Tenemos entonces que esta función educativa y socializadora que acometen los rituales no es sólo posicional —o sea: relativa a cuál es el sitio estructural de cada uno en relación con los demás-, ni tampoco es conductual — cuál es el comportamiento acertado para cada eventualidad-, sino que también es emocional, es decir relativa a cuáles son los sentimientos que cada individuo tiene que atesorar respecto de los distintos avatares que presenta su existencia social. Recordemos que ésta es la tesis central de un conocido artículo de Geertz (1987:339-372) sobre las peleas de gallos en Bali, en el cual resaltaba cómo ciertas celebraciones no sólo utilizan el miedo, la excitación, el placer..., antes sirven para recordar que es de estas emociones que la sociedad está hecha y que son estos sentimientos los que permiten a la sociedad estar cohesionada, unidos sus componentes. Las fiestas serían entonces recursos culturales al servicio de lo que, evocando la famosa novela de Flaubert, Geertz designa como la educación sentimental de los individuos. Esto no implica que los sentimientos escenificados en las fiestas sean realmente vividos por los participantes y espectadores, que suelen ser una misma cosa: las fiestas escenifican emociones, pero no para que todos aquellos que se comprometen en su realización las experimenten, sino para que los agentes sepan que estos sentimientos son la materia prima de la cual se nutre la vida social considerada deseable y que, obviamente, en el caso de las fiestas institucionalizadas o comercializadas, serán los deseos de aquellos que intenten servirse de las celebraciones para dominar.

Ahora bien, conviene remarcar que la fiesta, en tanto que magma energético hecho de acción pura y emociones pertinentes, puede conocer funciones y sentidos no sólo diversos, incluso contrapuestos, por no decir totalmente antagónicos. Paradigma de aquello que Marcel Mauss nombraba hecho social total, la fiesta es una arena donde visiones del mundo y proyectos sociales diferentes o hasta divergentes entran en contacto y se solapan. Como algunas pesquisas empíricas han puesto de manifiesto (Gómez García, 1992; Pujol y Antebi, 2006), en el marco temporal y espacial que establecen las fiestas, y sin que lleguen a saturarlo o lo monopolicen, encontramos de manera sincrónica diversas dosis de institucionalización política, económica o religiosa; diversas formas de intercambio económico; distintas gamas de ideas, conceptos, definiciones, sentimientos, valores..., no siempre bien definidos ni claramente compartimentados; variadas mecánicas de apropiación, de las instancias oficiales respecto de las producciones festivas más populares, pero también en sentido inverso; múltiples maneras de operar simbó- 
licamente, unificando identitariamente lo que era fragmentario y disperso, pero también haciendo estallar toda suerte de monolitismos, y rompiendo o cuestionando los anclajes que mantenían fijos a los individuos en sus respectivos grupos de adhesión... Todas estas pluralidades son las que podemos encontrar agitándose en el seno de las fiestas, poniendo de manifiesto que no es que éstas tengan una función, sino que son una función; que tienen una estructura, pero que sobre todo su tarea es la de estructurar o desestructurar no importa qué. Establecer sobre qué dimensión de la vida colectiva se ejercita en concreto esta fuerza social desencadenada, sea para reafirmarla o para disolverla, es justamente el enigma que el investigador o la investigadora de las fiestas ha de procurar resolver.

\section{Notas}

${ }^{1}$ En todo el texto, para referirme a grupos, del tipo que sean, utilizaré el plural masculino. Huelga decir que dentro de estos grupos contemplo el plural femenino, que sólo añadiré cuando quiera remarcarlo especialmente, para no hacer la lectura demasiado farragosa.

\section{Bibliografía}

Antebi, Andrés y Adrià Pujol, et al,. 2006, (Monografía pendiente de publicación en Barcelona, con el título provisional: Els Carnavals de Barcelona).

Ariño, Antonio, 1992, La ciudad ritual. La fiesta de las Fallas, Anthropos/Ministerio de Cultura, Barcelona/Madrid.

Balandier, Georges, 1990, El desorden. La teoría del caos y las ciencias sociales, Gedisa, Barcelona.

- 1994, El poder en escenas. Del poder de la representación a la representación del poder, Paidós, Barcelona.

Belascoain, Ricardo, 1985, El Carnaval... com a pretext, Aj. De Vilanova, Vilanova i la Geltrú.

Boissevain, J. (Ed.), 1992, Revitalizing European Rituals, Routledge, Londres.

Burke, Peter, 1997, La cultura popular en la Europa moderna, Altaza, Barcelona.
Cardini, Franco, 1984, Dias sagrados, Argos-Vergara, Barcelona.

Cruces, Francisco, 1992, "Cómo hacer cosas con programas. El proceso de producción de fiestas en Madrid”, en C. Cafarel, F. Bernete y V. Baca, (eds.), Comunicación y movimientos sociales, Diputación de Ciudad Real, Ciudad Real.

Delgado, Manuel, 1992, La festa a Catalunya, avui, Barcanova, Barcelona.

Delgado, Manuel; Antebi, Andrés; Horta, Gerard et al., 2004, Carrer, festa i revolta. Els usos simbòlics de l'espai públic a Barcelona (1951-2000), Inventari del Patrimoni Etnològic de Catalunya, Departament de Cultura, Generalitat de Catalunya, Barcelona.

Escalera, Javier, 1998, “Les festes com a patrimoni: reflexions sobre la festa a la ciutat contemporània a partir del cas de Sevilla", Fòrum Barcelona ciutat. Festa i ciutat, Institut de Cultura de Barcelona, Barcelona. pp. 9-22.

Frigolé, Joan, 1980, "Inversió simbòlica i identitat ètnica: una aproximació al cas de Catalunya", Quaderns de l'ICA, núm. 1.

García García, José Luis, 1994, “Celebraciones y conmemoraciones”, en Antropología, núm. 8 (octubre), pp. 113122.

Geertz, Clifford, 1987, La interpretación de las culturas, Gedisa, Barcelona.

Gil Calvo, Enrique, 1991, Estado de fiesta, Espasa-Calpe, Madrid.

Gilmore, David D, 1995, "El carnaval”, Agresividady comunidad. Paradojas de la cultura andaluza, Diputación Provincial de Granada, Granada, pp. 177-216.

Gómez García, Pedro, 1990, "Hipótesis sobre la estructura y la función de las fiestas”, P. Cordoba y J.-P. Étienvre, (ed.), La fiesta, la ceremonía, el rito, Casa de Velázquez/Universidad de Granada, Granada, pp. 51-63.

Handelman, D., 1990, Models a Mirrors: Toward an Anthropology of Public Events, Cambridge University Press, Nueva York.

Henningsen, Gustav, 2004, "El carnaval danés en su contexto europeo", en R. Jimeno Aranguren y J.I. Homobono, (eds.), Fiestas, rituales e identitades, Eusko Ikaskuntza, Donosita, pp. 337-346.

Hobsbawm, Eric y Thomas Ranger, 1988, L'invent de la tradició, Eumo, Vic.

Kaplan, Temma, 2002, Ciudad roja, periodo azul. Los movimientos sociales en la Barcelona de Picasso (1988-1939,), Península/ HCS, Barcelona. 
Le Roy Ladurie, Emmanuel, 1979 (2001), Le Carnaval de Romans, París, Gallimard.

Lévi-Strauss, Claude, 2001, El suplicio de Papá Noel, Mario Muchnik, Madrid.

Michonneau, Stéphanne, 2002, Barcelona: memòria i identitat. Monuments, commemoracions $i$ mite, Eumo, Vic.

Solé y Mauri, Belén, 1991, Festa i ideologies a Lleida. Interpretacions de la festa a la Lleida de la Restauració, Publicacions de l'Abadia de Montserrat, Barcelona.

Tambiah, S.J., 1985, Culture, Thought and Social Action, Harvard University Press, Cambridge.

Velasco, Honorio, 1982, "A modo de introducción: Tiempo de fiesta”, en H. Velasco, (ed.), Tiempo de fiesta. Ensayos antropológicos sobre las fiestas en España, Tres catorce diecisiete, Madrid, pp. 6-25.
—,1992, "El espacio transformado, el tiempo recuperado", en Antropología, núm. 2, pp. 3-31.

—,2000, “Tiempos modernos para fiestas tradicionales", en F.J. García Castaño (Eds.), Fiesta, tradición y cambio, Proyecto Sur de Ediciones, Granada.

Vovelle, Michel, 1978, Les métamorphoses de la fête en Provence (1750-1820), Aubier-Flammarion, París.

—,1985, "El desvío por la historia en el redescubrimiento de la fiesta", en Ideologias y mentalidades, Ariel, Barcelona, pp. 187-203.

-,1996, "La fiesta en el campo de la historia de las mentalidades", en Antropología, núm. 11, pp. 21-39. 